\title{
Flavour of natural and roasted Turkish hazelnut varieties (Corylus avellana L.) by descriptive sensory analysis, electronic nose and chemometrics
}

\author{
Cesarettin Alasalvar, ${ }^{1 *}$ Ebru Pelvan, ${ }^{1}$ Banu Bahar, ${ }^{1}$ Figen Korel $^{2}$ \& Hülya Ölmez ${ }^{1}$ \\ 1 TÜBITAK Marmara Research Centre, Food Institute, PO Box 21, 41470 Gebze, Kocaeli, Turkey \\ 2 Department of Food Engineering, Izmir Institute of Technology, 35430 Urla, Izmir, Turkey
}

(Received 23 May 2011; Accepted in revised form 13 September 2011)

\begin{abstract}
Summary A total of eighteen natural and roasted hazelnut varieties (amongst which only Tombul variety is classified as prime quality), grown in the Giresun province of Turkey, were compared for their differences in descriptive sensory analysis (DSA), electronic nose (e-nose) data and chemometrics. Differences in some descriptive of DSA between natural and roasted hazelnuts as well as within the varieties were observed. Although Tombul hazelnut was selected as one of the best varieties in terms of flavour attributes and received the highest intensities in general, no significant differences $(P>0.05)$ existed among hazelnut varieties except in certain flavour attributes ('after taste' and 'nutty'). DSA and e-nose data of natural and roasted hazelnuts were also evaluated for discrimination using principal component analysis (PCA) and cluster analysis. Results of PCA using e-nose data showed that extracted principal components explained $99.7 \%$ and $99.8 \%$ of the total variance of the data for natural and roasted hazelnut varieties, respectively. Both DSA and e-nose can be used for discrimination of natural and roasted hazelnuts.
\end{abstract}

Keywords Chemometrics, descriptive sensory analysis, electronic nose, flavour, flavour attributes, natural hazelnuts, roasted hazelnuts.

\section{Introduction}

Hazelnut (Corylus avellana L.) belongs to the Betulaceae family, and is a popular tree nut worldwide; it is mainly distributed along the coasts of the Black Sea region of Turkey, southern Europe (Italy, Spain, Portugal and France) and in some areas of the United States (Oregon and Washington). Hazelnut is also grown in New Zealand, China, Azerbaijan, Chile, Iran and Georgia. Turkey is the world's largest producer of hazelnuts (510 $000 \mathrm{MT}$ in 2011, in shell basis), contributing around $63.6 \%$ to the total global production, followed by Italy $(15.6 \%)$, Azerbaijan (5.6\%), Georgia (4.4\%), the United States $(4.3 \%)$ and Spain $(3.1 \%)$. Other countries contribute only $3.4 \%$ to the total production (INC, 2011).

Eighteen varieties (Acı, Cavcava, Çakıldak, Foşa, Ham, Incekara, Kalınkara, Kan, Karafındık, Kargalak, Kuş, Mincane, Palaz, Sivri, Tombul, Uzunmusa, Yassı Badem and Yuvarlak Badem) of hazelnuts are cultivated in Turkey (Alasalvar et al., 2010a,b). Among these varieties, only Tombul (round) hazelnut, mainly

*Correspondent: Fax: +90 2626412309 ;

e-mail: cesarettin.alasalvar@mam.gov.tr grown in the Giresun province, is classified as prime quality (also known as Giresun quality) due to its high oil content, distinctive taste and aroma, and easily and quickly removable brown skin during roasting. The remaining varieties grown in all parts of Turkey are known as second-grade quality (also known as Levant quality) (Alasalvar et al., 2010b).

Besides its potential health benefits and nutritional value (Mercanligil et al., 2007; Alasalvar \& Shahidi, 2009; Alasalvar et al., 2009; Yücesan et al., 2010), hazelnut as a food ingredient provides a unique and distinctive flavour (Alasalvar et al., 2003, 2004, 2010a; Burdack-Freitag \& Schieberle, 2010) and a pleasant crispness (Saklar et al., 2001).

In the flavour research, sensory evaluation is essential because of its high sensitivity and the ability to describe sensory properties. Descriptive sensory analysis (DSA) has been successfully used to obtain detailed descriptions of the smell, taste and mouth feel of foods and beverages (Alasalvar et al., 2003; Morita et al., 2003; Leighton et al., 2010). DSA provides descriptive terms for attributes and allows quantification of their perceived intensities. Moreover, it provides qualitative and quantitative comparisons of the model against the product (Cadwallader, 2010). The electronic nose 
(e-nose) has proven to be a rapid tool to screen food quality and aroma, but mostly e-nose is required for correlation with sensory scores (Gardner \& Hines, 1997; Korel \& Balaban, 2002; Drake et al., 2003; Kadiroğlu et al., 2011).

Hazelnut may be consumed naturally or preferably roasted. The main purpose of roasting is to improve the desirable flavour, colour, crispness and crunchy texture of the product (Langourieux et al., 2000; Saklar et al., 2001; Alasalvar et al., 2003; Burdack-Freitag \& Schieberle, 2010). As mentioned above, only Tombul hazelnut is classified as prime-grade quality, and the remaining varieties are known as second-grade quality. Although one of the criteria for this selection is distinctive taste and aroma, detailed information is limited as to the reasons for superior quality of Tombul hazelnut in terms of its flavour. As a parallel to this study, we assessed the effect of roasting on taste-active components (sugars, organic acids, free phenolic acids and condensed tannins) of eighteen native Turkish hazelnut varieties and to examine whether taste-active components could differentiate the prime-and secondgrade quality hazelnuts (Alasalvar et al., 2010a). We found that roasting had a significant effect on the loss of condensed tannins and free phenolic acids (gallic acid) due to the removal of the brown skin. In addition, differences existed in the sugar and organic acid contents between natural and roasted hazelnut varieties. Furthermore, based on the results of this parallel study, prime-and second-grade natural and roasted hazelnut varieties cannot be distinguished on the basis of their taste-active components. Therefore, we attempted to look at DSA and e-nose, which may lead to true characterisation of natural and roasted hazelnut varieties as well as prime-and second-grade natural and roasted hazelnut varieties. The objectives of this study were to discriminate natural and roasted hazelnut varieties using DSA and e-nose analyses based on aroma profiles using principal component analysis (PCA) and cluster analysis (CA).

\section{Materials and methods}

\section{Samples}

Eighteen sun-dried ( 3 days at approximately $20-25^{\circ} \mathrm{C}$ ) native Turkish hazelnut varieties (namely Acı, Cavcava, Çakıldak, Foşa, Ham, Incekara, Kalınkara, Kan, Karafındık, Kargalak, Kuş, Mincane, Palaz, Sivri, Tombul, Uzunmusa, Yassi Badem and Yuvarlak Badem) were procured from Hazelnut Research Institute (Giresun, Turkey) at the beginning of the harvest season of 2008. All hazelnut varieties (1 $\mathrm{kg}$ was sampled from $10 \mathrm{~kg}$ of each hazelnut variety), were obtained from the same location/field to make a true comparison. The samples were kept in their shell in a temperature- control cabinet (at $5{ }^{\circ} \mathrm{C}$ with relative humidity of 65 $70 \%$ ) at the Food Institute (TÜBITAK Marmara Research Centre, Gebze, Turkey) prior to analyses. All samples were analysed within 2 months of arrival and shelled before analysis.

\section{Reagents and standards}

All chemical reagents were purchased from SigmaAldrich-Fluka Co. Ltd. (Prolab, Istanbul, Turkey), unless otherwise stated.

\section{Roasting of hazelnuts}

Before roasting, the hazelnuts were cracked and then kept at room temperature for $3 \mathrm{~h}$. Samples were roasted at $140{ }^{\circ} \mathrm{C}$ for $30 \mathrm{~min}$ with an air velocity of $1 \mathrm{~m} \mathrm{~s}^{-1}$ (model CS02-KF Hazelnut Roasting Oven; Ceselsan Machinery Ltd., Giresun, Turkey). The temperature and time were maintained as the same for all hazelnut samples regardless of their kernel size. The roasting was performed in triplicate for each variety.

\section{Descriptive sensory analysis}

Both natural and roasted hazelnuts were assessed using a flavour profile method described previously (Alasalvar et al., 2003). DSA was employed for evaluation of the natural and roasted hazelnut varieties, using a $80 \mathrm{~mm}$ long line with line anchors of $0=$ none and $80=$ very, by ten well-trained panellists (five males and five females, aged 28-43 years).

Prior to DSA, panellists discussed the flavour properties of both natural and roasted hazelnut samples during three preliminary orientation sessions, each lasting $90 \mathrm{~min}$, until they had agreed on their use as flavour attributes. During these orientation experiments, panellists evaluated five different coded natural and roasted hazelnut varieties; fourteen flavour attributes by observing odour, taste and mouth feel ('after taste', 'bitter', 'burnt', 'buttery/caramel-like', 'coffee-like', 'fatty', 'fruity', 'green', 'nutty', 'rancid', 'roasty/popcorn-like', 'sour', 'sweet' and 'woody') were identified. The flavour attributes together with their definitions, standards and reference materials used are given in Table 1. Among these flavour attributes, 'burnt', 'coffeelike' and 'roasty/popcorn-like' were only used for roasted hazelnut varieties. Standards and reference materials were made available for panellists when a consensus agreement was attained. Natural and freshly roasted (1 h after roasting) hazelnut samples (10-g portion for each sample) were presented randomly to each panellist to evaluate (samples were evaluated twice). Each sample was coded with a three-digit random number. Five percent sugar solution was used for assessing the sweetness, as hazelnut contains around 
Flavour and sensory quality of natural and roasted Turkish hazelnuts C. Alasalvar et al.

Table 1 Flavour attributes with definitions, standards and reference materials used for descriptive sensory analysis

\begin{tabular}{|c|c|c|}
\hline Attribute $^{a}$ & Sensory attribute definitions & Standards and reference materials \\
\hline After taste & $\begin{array}{l}\text { Remaining desirable and delicate } \\
\text { flavour after swallowing }\end{array}$ & No reference was used \\
\hline Bitter & Taste associated with caffeine & Diluted caffeine solution $\left(0.195 \mathrm{~L}^{-1}\right)$ \\
\hline Burnt ${ }^{b}$ & Smell grilled meat, burnt smell & Over roasted hazelnut (at $200^{\circ} \mathrm{C}$ for $20 \mathrm{~min}$ ) \\
\hline Buttery/caramel-like & Flavour of burnt sugar or butter & Burnt cream/burnt sugar \\
\hline Coffee-like $^{b}$ & Flavour of coffee & Freshly ground coffee sample or dark chocolate \\
\hline Fatty & Oily taste or mouth feel & Taste of hazelnut or vegetable oils \\
\hline Fruity & $\begin{array}{l}\text { Delicate, desirable, fruity flavour } \\
\text { associated of most fruits }\end{array}$ & Diluted food-grade hexane solution $\left(0.005 \mathrm{~g} \mathrm{~L}^{-1}\right)$ \\
\hline Green & Odour cut leaves of green plants & Fresh grass or green hazelnut leaves \\
\hline Nutty & $\begin{array}{l}\text { Delicate, characteristics flavour } \\
\text { of tree nut products }\end{array}$ & Taste of hazelnut, almond, or walnut \\
\hline Rancid & Associated with old or oxidised fat & Oxidised hazelnut or fish oils \\
\hline Roasty/popcorn-like ${ }^{\text {b }}$ & Flavour of roasted meat & $\begin{array}{l}\text { Commercially marketed roasted hazelnut } \\
\text { and popcorn }\end{array}$ \\
\hline Sour & Taste associated with citric acid & Diluted citric acid solution $\left(0.43 \mathrm{~g} \mathrm{~L}^{-1}\right)$ \\
\hline Sweet & Taste associated with sugar or sweetener & Diluted sucrose solution (5\%) \\
\hline Woody & Odour of hazelnut hard shell or hazelnut tree & Hazelnut wood or hard shell \\
\hline
\end{tabular}

${ }^{a}$ Flavour attributes were selected by observing odour, taste and mouth fell of five different coded natural and roasted hazelnut varieties.

bonly for roasted hazelnut varieties.

3.5-6\% sugars (Alasalvar et al., 2010a). Sweetness was evaluated using a $80 \mathrm{~mm}$-long line with line anchors of $0 \%=$ none and $5 \%=$ very. Data are expressed as mean $\pm \mathrm{SD}(n=10$ well-trained panellists).

\section{Electronic nose (e-nose)}

The aroma profiles of natural and roasted hazelnut varieties were investigated using an e-nose (model MOSES II; Lennartz Electronic GmbH, Tübingen, Germany) equipped with eight different quartz micro balance sensors and eight different semi-conductive metal oxide sensors. The e-nose analysis was carried out according to Alasalvar et al. (2004) with slight modifications. Eight replicate vials for each of the eighteen varieties of grated (approximately $3-4 \times 1 \mathrm{~mm}$ ) natural and roasted hazelnuts $(2 \mathrm{~g}$ each) were flushed with compressed air for about $10 \mathrm{~s}$ prior to analysis. The hazelnut vial was then placed in the autosampler of the e-nose. The vial was purged with compressed air for 2 min to eliminate any foreign odour present in the vial, and the sensor head was purged for 4 min. During this time, the sample volatiles were allowed to equilibrate in the headspace of the vial. Sensor response data were acquired for $4 \mathrm{~min}$. Total analysis time for each hazelnut sample was $10 \mathrm{~min}$. Readings at $4 \mathrm{~min}$ exposure of the sensors were used for data analysis. Data are expressed as eight replicate vials for each of the eighteen varieties.

\section{Statistical analysis}

The statistical significance of the sensory attributes of hazelnut varieties were evaluated by non-parametric test with 5\% significance level (Kruskal-Wallis, XLSTAT, version 2009/05/01; Addinsoft, Paris, France). Differences at $P<0.05$ were considered to be significant. PCA and CA were performed to discriminate and form clusters among natural and roasted hazelnut samples based on their flavour fingerprints obtained by the DSA and e-nose using SIMCA software (Umetrics, Umeå, Sweden) and Statistica software (StatSoft Inc., Tulsa, OK, USA), respectively. Before performing PCA and CA, the e-nose and DSA data were standardised by subtracting each row of a data matrix from its mean value and then dividing it by its standard deviation. PCA is an unsupervised technique that reduces the dimensionality in a data set, calculates a number of principal components (PCs) having the greatest variance and allows the visualisation of clusters. CA is also an unsupervised classification technique that involves a measurement of the similarity among hazelnut samples to be clustered. For CA, the complete linkage method was used, and the measurement of the similarity was determined using the square of Euclidean distance.

\section{Results and discussion}

Descriptive sensory analysis and its correlation with principal component analysis and cluster analysis

Tables 2 and 3 show the DSA of flavour attributes in eighteen varieties of natural and roasted hazelnuts, respectively. Intensities for a number of flavour attributes were assessed. Flavour attributes of 'burnt', 'roasty/popcorn-like' and 'coffee-like' in roasted hazelnuts and 'green' in natural hazelnuts were only detected. 
Table 2 Descriptive sensory analysis of flavour attributes in eighteen natural hazelnut varieties (scaling: $0=$ none, $80=$ very)

\begin{tabular}{|c|c|c|c|c|c|c|c|c|c|}
\hline Variety & After taste & Bitter & $\begin{array}{l}\text { Buttery/ } \\
\text { cramel-like }\end{array}$ & Fatty & Fruity & Green & Nutty & Sweet & Woody \\
\hline$A_{C 1}$ & $55.5 \pm 11.2^{\mathrm{ab}}$ & $2.0 \pm 4.2^{\mathrm{a}}$ & $23.0 \pm 14.9^{\mathrm{a}}$ & $47.0 \pm 12.3^{\mathrm{a}}$ & $21.0 \pm 26.3^{\mathrm{a}}$ & $8.5 \pm 12.0^{\mathrm{a}}$ & $58.5 \pm 7.1^{\mathrm{ab}}$ & $47.5 \pm 20.6^{\mathrm{a}}$ & $10.5 \pm 10.4^{\mathrm{a}}$ \\
\hline Cavcava & $49.0 \pm 14.7^{\mathrm{ab}}$ & $4.5 \pm 5.0^{a}$ & $31.5 \pm 23.1^{a}$ & $50.0 \pm 8.2^{\mathrm{a}}$ & $24.0 \pm 23.5^{\mathrm{a}}$ & $12.5 \pm 12.3^{\mathrm{a}}$ & $54.0 \pm 12.4^{\mathrm{ab}}$ & $41.5 \pm 15.3^{a}$ & $28.0 \pm 16.2^{\mathrm{a}}$ \\
\hline Çakıldak & $6.5 \pm 15.5^{\mathrm{ab}}$ & $2.0 \pm 4.2^{\mathrm{a}}$ & $25.0 \pm 16.0^{a}$ & $39.0 \pm 15.4^{\mathrm{a}}$ & $22.0 \pm 20.0^{\mathrm{a}}$ & $16.0 \pm 15.1^{\mathrm{a}}$ & $47.0 \pm 16.4^{\mathrm{ab}}$ & $38.5 \pm 15.8^{a}$ & $20.5 \pm 17.1^{a}$ \\
\hline Foşa & $51.5 \pm 15.1^{\mathrm{ab}}$ & $2.0 \pm 3.5^{a}$ & $24.0 \pm 15.1^{a}$ & $44.5 \pm 13.6^{a}$ & $26.0 \pm 23.5^{\mathrm{a}}$ & $15.5 \pm 15.4^{\mathrm{a}}$ & $53.0 \pm 11.8^{\mathrm{ab}}$ & $1.5 \pm 12.7^{a}$ & $15.0 \pm 16.5^{a}$ \\
\hline Ham & $55.5 \pm 16.2^{\mathrm{ab}}$ & $0.0 \pm 0.0^{\mathrm{a}}$ & $29.5 \pm 15.2^{\mathrm{a}}$ & $45.0 \pm 12.5^{\mathrm{a}}$ & $24.5 \pm 19.4^{\mathrm{a}}$ & $13.0 \pm 13.2^{\mathrm{a}}$ & $58.5 \pm 12.5^{\mathrm{ab}}$ & $45.0 \pm 16.7^{\mathrm{a}}$ & $16.5 \pm 18.6^{a}$ \\
\hline İncekara & $3.5 \pm 14.3^{\mathrm{ab}}$ & $3.0 \pm 4.8^{\mathrm{a}}$ & $31.0 \pm 22.2^{\mathrm{a}}$ & $50.5 \pm 9.0^{\mathrm{a}}$ & $23.0 \pm 24.3^{\mathrm{a}}$ & $11.5 \pm 12.0^{\mathrm{a}}$ & $57.0 \pm 10.1^{\mathrm{ab}}$ & $48.5 \pm 17.0^{\mathrm{a}}$ & $25.0 \pm 16.8^{a}$ \\
\hline Kalınkara & $6.0 \pm 13.1^{\mathrm{ab}}$ & $0.0 \pm 0.0^{\mathrm{a}}$ & $29.0 \pm 15.8^{\mathrm{a}}$ & $50.0 \pm 9.4^{\mathrm{a}}$ & $23.5 \pm 23.9^{\mathrm{a}}$ & $7.0 \pm 10.6^{\mathrm{a}}$ & $62.5 \pm 6.8^{\mathrm{ab}}$ & $47.5 \pm 16.9^{\mathrm{a}}$ & $7.5 \pm 7.2^{\mathrm{a}}$ \\
\hline Karafındık & $52.0 \pm 11.6^{a b}$ & $0.5 \pm 1.6^{a}$ & $24.0 \pm 16.3^{a}$ & $45.5 \pm 11.9^{\mathrm{a}}$ & $19.0 \pm 23.2^{\mathrm{a}}$ & $9.5 \pm 12.1^{\mathrm{a}}$ & $53.0 \pm 8.6^{\mathrm{ab}}$ & $39.0 \pm 18.4^{\mathrm{a}}$ & $13.5 \pm 9.4^{\mathrm{a}}$ \\
\hline Kargalak & $44.5 \pm 12.1^{a}$ & $6.0 \pm 5.2^{a}$ & $24.7 \pm 16.6^{a}$ & $44.0 \pm 9.9^{\mathrm{a}}$ & $20.0 \pm 18.1^{\mathrm{a}}$ & $15.5 \pm 18.9^{\mathrm{a}}$ & $49.0 \pm 12.9^{a}$ & $29.5 \pm 10.4^{a}$ & $24.0 \pm 19.0^{a}$ \\
\hline Kan & $51.5 \pm 11.8^{\mathrm{ab}}$ & $0.0 \pm 0.0^{\mathrm{a}}$ & $36.5 \pm 19.4^{\mathrm{a}}$ & $52.0 \pm 10.6^{a}$ & $27.0 \pm 23.5^{\mathrm{a}}$ & $16.0 \pm 18.8^{\mathrm{a}}$ & $57.5 \pm 12.3^{a b}$ & $39.5 \pm 15.0^{\mathrm{a}}$ & $21.5 \pm 19.2^{\mathrm{a}}$ \\
\hline Kuş & $53.0 \pm 17.8^{\mathrm{ab}}$ & $0.0 \pm 0.0^{\mathrm{a}}$ & $34.5 \pm 22.9^{a}$ & $53.5 \pm 10.3^{a}$ & $33.0 \pm 24.6^{a}$ & $14.0 \pm 11.7^{\mathrm{a}}$ & $54.5 \pm 13.4^{\mathrm{ab}}$ & $52.5 \pm 8.2^{\mathrm{a}}$ & $15.5 \pm 18.6^{\mathrm{a}}$ \\
\hline Mincane & $56.0 \pm 11.3^{\mathrm{ab}}$ & $1.5 \pm 3.4^{\mathrm{a}}$ & $30.0 \pm 15.1^{a}$ & $52.0 \pm 10.3^{a}$ & $21.0 \pm 18.5^{\mathrm{a}}$ & $10.0 \pm 10.3^{a}$ & $60.0 \pm 8.2^{\mathrm{ab}}$ & $44.5 \pm 20.2^{\mathrm{a}}$ & $8.5 \pm 7.8^{a}$ \\
\hline Palaz & $56.5 \pm 13.1^{\mathrm{ab}}$ & $0.0 \pm 0.0^{\mathrm{a}}$ & $36.5 \pm 21.7^{a}$ & $55.0 \pm 9.7^{\mathrm{a}}$ & $24.5 \pm 23.3^{\mathrm{a}}$ & $14.0 \pm 14.9^{\mathrm{a}}$ & $61.0 \pm 10.2^{\mathrm{ab}}$ & $46.5 \pm 16.7^{a}$ & $28.5 \pm 18.6^{a}$ \\
\hline Sivri & $55.0 \pm 11.1^{a b}$ & $0.0 \pm 0.0^{\mathrm{a}}$ & $35.5 \pm 19.2^{\mathrm{a}}$ & $51.5 \pm 9.1^{\mathrm{a}}$ & $30.0 \pm 25.5^{\mathrm{a}}$ & $17.0 \pm 14.0^{\mathrm{a}}$ & $56.0 \pm 10.7^{\mathrm{ab}}$ & $44.0 \pm 12.2^{\mathrm{a}}$ & $21.5 \pm 17.2^{\mathrm{a}}$ \\
\hline Tombul & $65.5 \pm 6.4^{b}$ & $0.0 \pm 0.0^{\mathrm{a}}$ & $43.5 \pm 23.8^{a}$ & $56.5 \pm 3.4^{\mathrm{a}}$ & $42.0 \pm 17.4^{\mathrm{a}}$ & $12.5 \pm 15.1^{\mathrm{a}}$ & $67.5 \pm 5.9^{b}$ & $46.0 \pm 13.5^{a}$ & $17.0 \pm 19.0^{a}$ \\
\hline Uzunmusa & $47.0 \pm 10.6^{\mathrm{ab}}$ & $4.5 \pm 5.0^{\mathrm{a}}$ & $33.5 \pm 18.9^{a}$ & $48.0 \pm 7.9^{\mathrm{a}}$ & $27.5 \pm 20.2^{\mathrm{a}}$ & $12.5 \pm 14.4^{\mathrm{a}}$ & $53.0 \pm 9.2^{\mathrm{ab}}$ & $43.5 \pm 14.2^{\mathrm{a}}$ & $18.4 \pm 18.9^{a}$ \\
\hline Yassı Badem & $48.0 \pm 13.0^{\mathrm{ab}}$ & $2.5 \pm 4.2^{\mathrm{a}}$ & $20.5 \pm 15.0^{\mathrm{a}}$ & $42.0 \pm 11.6^{\mathrm{a}}$ & $17.5 \pm 23.7^{\mathrm{a}}$ & $16.0 \pm 12.6^{a}$ & $52.5 \pm 8.9^{\mathrm{ab}}$ & $36.5 \pm 13.8^{\mathrm{a}}$ & $16.0 \pm 9.9^{a}$ \\
\hline Yuvarlak Badem & $50.0 \pm 13.3^{a b}$ & $6.0 \pm 5.2^{\mathrm{a}}$ & $27.5 \pm 24.7^{a}$ & $49.0 \pm 11.3^{\mathrm{a}}$ & $25.0 \pm 23.8^{\mathrm{a}}$ & $12.5 \pm 12.3^{\mathrm{a}}$ & $50.0 \pm 18.1^{a b}$ & $44.0 \pm 17.9^{\mathrm{a}}$ & $25.5 \pm 16.9^{a}$ \\
\hline
\end{tabular}

Data are expressed as mean $\pm \mathrm{SD}$ ( $n=10$ well-trained panellists).

Means \pm SD followed by the same letter, within a column, are not significantly different $(P>0.05)$.

Sweet was evaluated using a $80 \mathrm{~mm}$-long line with line anchors of $0 \%=n o n e$ and $5 \%=$ very.

Rancid and sour notes were not detected in natural hazelnuts.

In general, 'nutty', 'after taste', 'oily', 'sweet', 'buttery/caramel-like', 'fruity' and 'woody' were predominant flavour attributes in natural hazelnuts, whereas 'roasty/popcorn-like', 'nutty', 'after taste', 'oily', 'sweet', 'coffee-like', 'buttery/caramel-like' and 'fruity' notes were predominant in roasted hazelnuts in descending intensities. Contributions of the overall flavour attributes of 'green' and 'bitter' in natural hazelnuts and 'burnt', 'bitter' and 'woody' in roasted hazelnuts were weak in descending intensities. As a result of the freshness of the hazelnut varieties, 'rancid' and 'sour' notes were not detected in any of the natural or roasted hazelnuts. However, 'bitter', 'sour' and 'rancid' flavour attributes may develop during storage as a result of oxidation (Alasalvar et al., 2003). Recently, BurdackFreitag \& Schieberle (2010) measured the aroma profile analysis using a sensory panel and key odorants in natural and roasted Italian hazelnuts. In the aroma profile of the natural hazelnuts, an intense 'fruity-nutty' aroma predominated, followed by 'fatty' and 'green' attributes. In the roasted hazelnuts, however, 'popcornlike', 'coffee-like' and 'sweet-smoky' aroma attributes predominated, whereas the 'fruity', 'nutty' and 'fatty' odour was not increased when compared with the natural hazelnuts. The present results are in agreement with those of Burdack-Freitag \& Schieberle (2010).

Overall, intensities for a number of flavour attributes such as 'after taste', 'nutty', 'oily' and 'sweet' were significantly higher $(P<0.01)$ in roasted hazelnuts than those of natural counterparts (Tables 2 and 3). How- ever, in natural hazelnuts 'buttery/caramel-like', 'fruity' and 'woody' notes were rated significantly higher $(P<0.01)$ than in their roasted counterparts. Intensities for the 'bitter' flavour attribute were not significantly different $(P>0.05)$ between natural and roasted hazelnuts. These results are, in general, comparable with those published in the literature (Alasalvar et al., 2003) for Tombul variety of natural and roasted hazelnuts.

Despite the fact that Tombul variety had the highest sensory intensities for 'after taste', 'buttery/caramellike', 'fruity', 'nutty' and 'oily' in natural hazelnuts for 'after taste', 'fruity', 'roasty/popcorn-like', 'nutty' and 'oily' in roasted hazelnuts, no significant differences existed $(P>0.05)$ among flavour attributes of eighteen natural hazelnut varieties, except between Tombul and Kargalak for 'after taste' and 'nutty' attributes. For roasted hazelnut varieties, only Tombul variety was significantly different $(P<0.05)$ from Yassi Badem and Yuvarlak Badem for 'after taste' and 'nutty' attributes. Other flavour attributes showed no significant differences $(P>0.05)$ among hazelnuts. In both natural and roasted hazelnuts, 'sweet' note received the highest intensity in Kuş variety which has been reported to have the highest sugar content ( $4.08 \mathrm{~g}$ per $100 \mathrm{~g}$ in natural and $5.52 \mathrm{~g}$ per $100 \mathrm{~g}$ in roasted hazelnut), among all hazelnuts tested (Alasalvar et al., 2010a).

Descriptive sensory analysis data were also analysed using PCA to determine the discrimination of the samples based on hazelnut varieties. The flavour attributes obtained by the panellists were used as the 


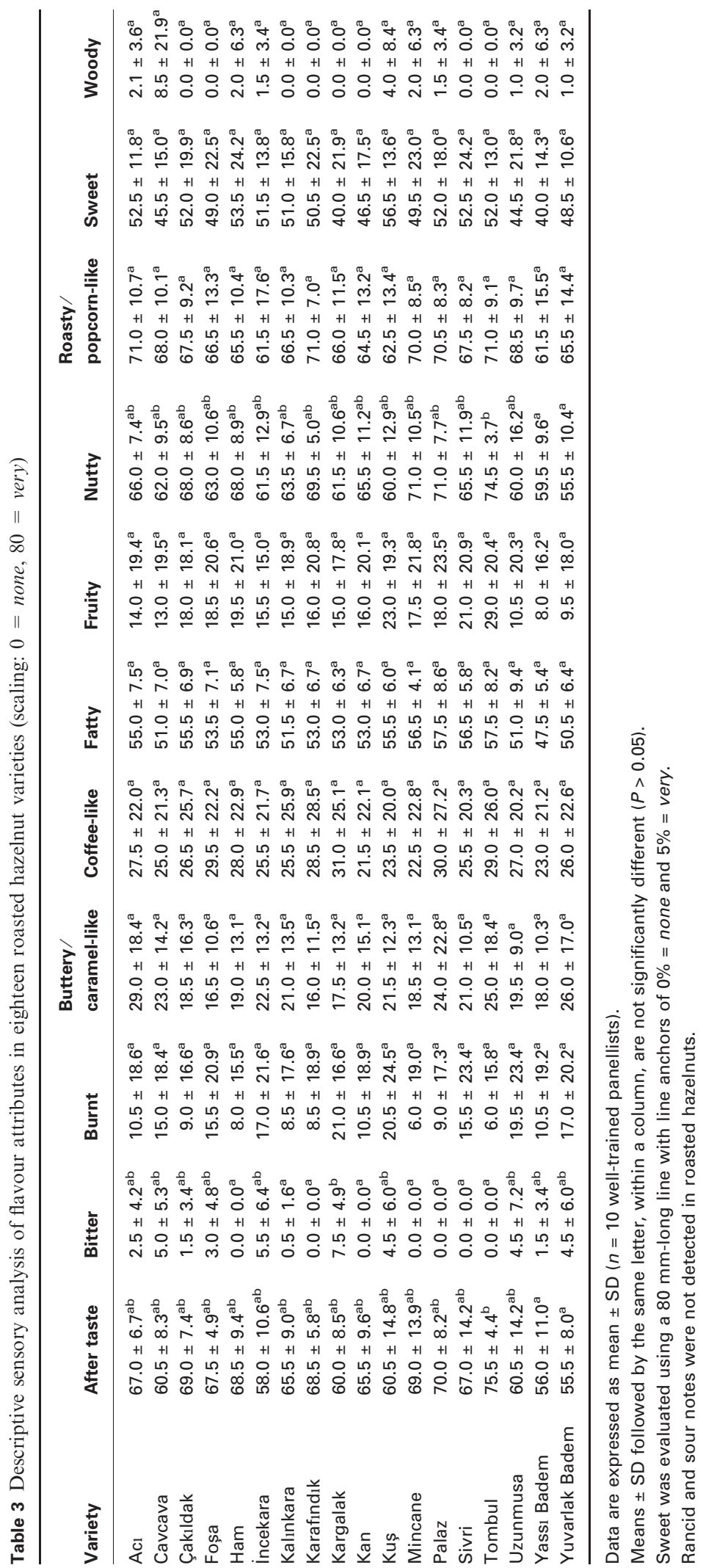



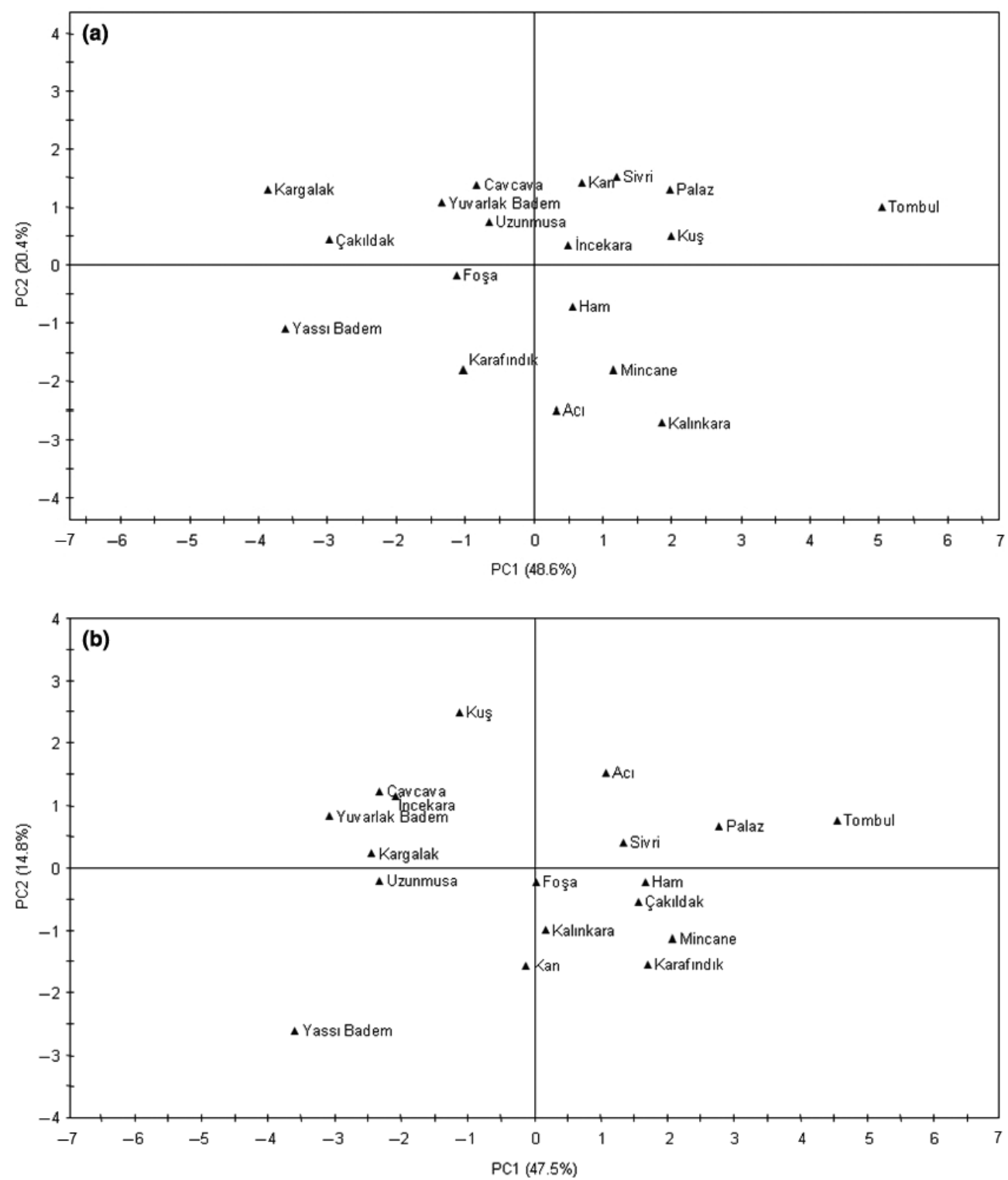

Figure 1 Principal component analyses for descriptive sensory analysis (DSA) data among eighteen natural (a) and roasted (b) hazelnut varieties (natural hazelnuts: $\mathrm{PC}=2, r_{\mathrm{X}}^{2}=0.69, Q_{\mathrm{cum}}^{2}=0.282, \mathrm{PC} 1=48.6 \%$, and $\mathrm{PC} 2=20.4 \%$ and roasted hazelnuts: $\mathrm{PC}=4, r_{\mathrm{X}}^{2}=0.857$, $Q_{\text {cum }}^{2}=0.238, \mathrm{PC} 1=47.5 \%$, and $\left.\mathrm{PC} 2=14.8 \%\right)$.

variables in PCA analysis. Figure 1 shows the score plots of the first two PCs from the DSA data of natural and roasted hazelnut samples. As shown Fig. 1a, the first two PCs explained $69 \%$ of the total variance of the data (PC1: $48.6 \%$ and PC2: $20.4 \%$ ). No distinct clusters were obtained in this plot and Tombul hazelnut was found to be away from the rest of the varieties. In Fig. 1b, four PCs were extracted and accounted together for $85.7 \%$ of the variability in roasted hazelnuts. The first two PCs
(PC1 and PC2) accounted for $47.5 \%$ and $14.8 \%$ of variance, respectively. No distinct clusters were also observed among hazelnut varieties, and Tombul hazelnut was located away from the rest of the varieties.

With respect to CA that was also performed to analyse the DSA data. The measurement of similarity was based on the square Euclidean distance, and the cluster method was the complete linkage. The position of the line on the scale showed the distance at which 

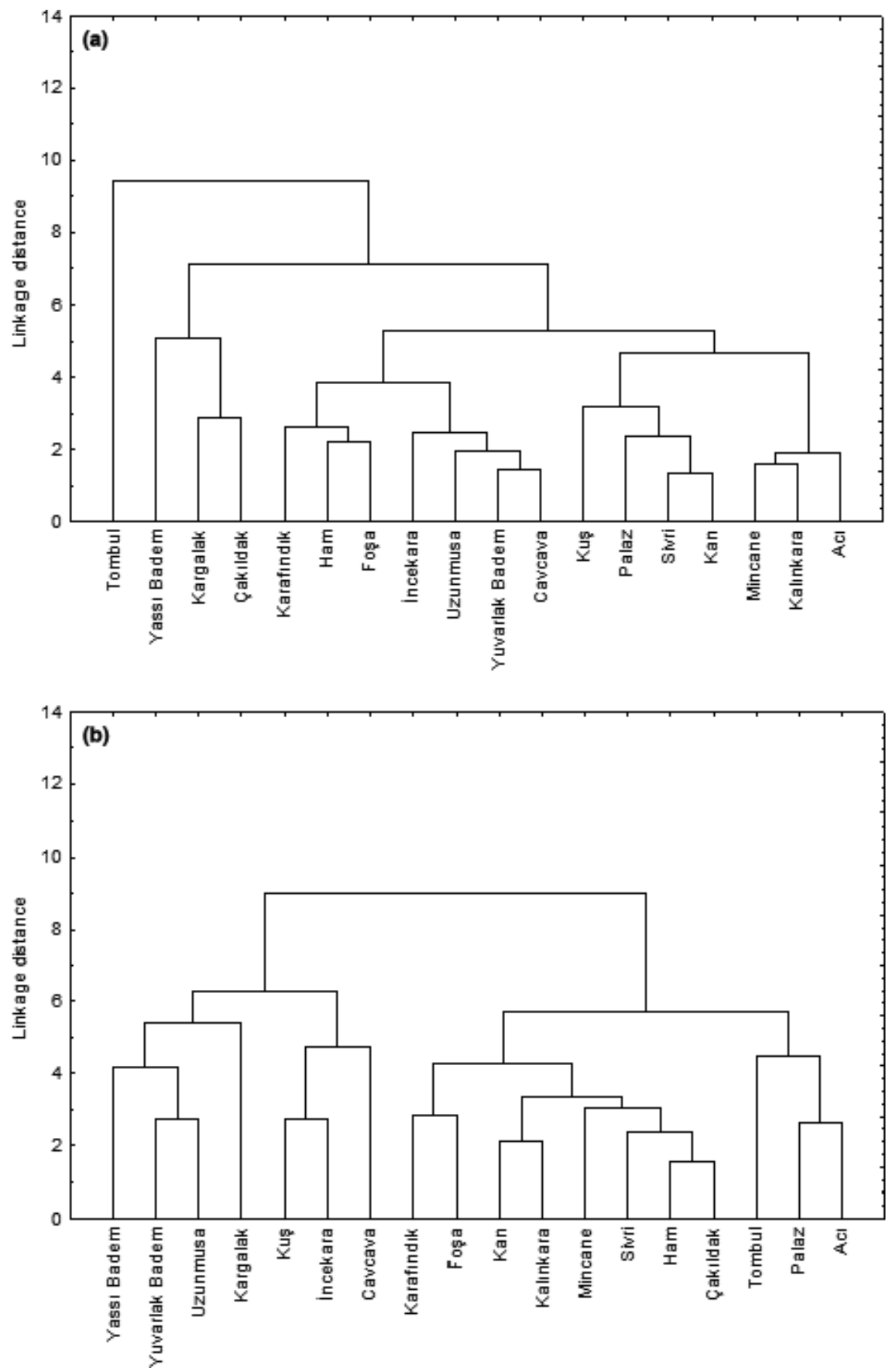

Figure 2 Cluster analyses for descriptive sensory analysis (DSA) data among eighteen natural (a) and roasted (b) hazelnut varieties.

clusters were joined. Figure 2 shows the dendrograms of the natural (a) and roasted (b) hazelnuts. Four clusters based on DSA of natural hazelnut data were observed (Fig. 2a). Tombul variety was separated from other clusters, showing that sensory intensities of this variety were different from others. As can be seen from Fig. 2b, roasted Tombul hazelnut was located close to Palaz and Ac1 varieties. 

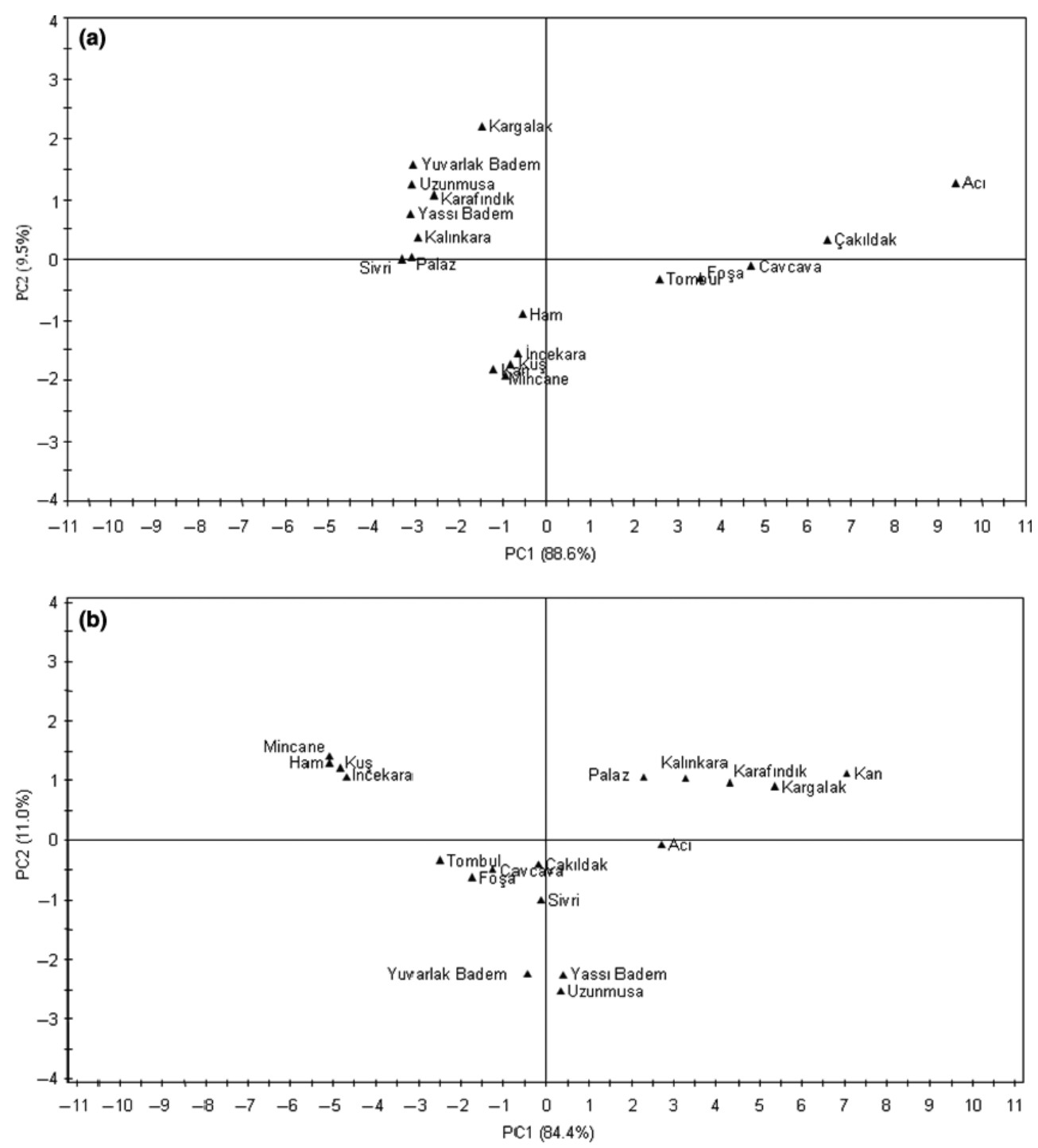

Figure 3 Principal component analyses for e-nose data among eighteen natural (a) and roasted (b) hazelnut varieties (natural hazelnuts: PC $=4$, $r_{\mathrm{X}}^{2}=0.99, Q_{\text {cum }}^{2}=0.97, \mathrm{PC} 1=88.6 \%$, and $\mathrm{PC} 2=9.5 \%$ and roasted hazelnuts: $\mathrm{PC}=5, r_{\mathrm{X}}^{2}=0.99, Q_{\text {cum }}^{2}=0.98, \mathrm{PC} 1=84.4 \%$, and $\mathrm{PC} 2=11 \%$ ).

Electronic nose and its correlation with principal component analysis and cluster analysis

E-nose data were analysed using PCA to determine the discrimination of the samples based on hazelnut varieties. The score plots of the first two PCs from e-nose data of natural and roasted hazelnut samples are presented in Fig. 3. Four PCs were extracted and accounted together for $99.7 \%$ of the variability in the original data of natural hazelnuts (Fig. 3a). PC1 and PC2 accounted for $88.6 \%$ and $9.5 \%$ of variance, respectively. Three different clusters, (Tombul, Foşa, Cavcava and Çakıldak), (Kargalak, Yuvarlak
Badem, Uzunmusa, Karafındık, Yassı Badem, Kalınkara, Palaz and Sivri) and (Ham, Incekara, Kuş, Kan and Mincane), were formed among natural hazelnut varieties. In addition, Ac1 variety was located away from the rest of the varieties. As shown in Fig. 3b, five PCs were extracted and explained $99.8 \%$ of the variance of the e-nose data for roasted hazelnuts. PC1 and PC2 explained $84.4 \%$ and $11.0 \%$ of the variance, respectively. Acr variety was found to be away from the rest of the varieties. In addition to this cluster, four different clusters, (Tombul, Foşa, Cavcava, Çakıldak and Sivri), (Palaz, Kalınkara, Karafindık, Kargalak and Kan), (Mincane, Ham, Kuş and Incekara) and (Yuvarlak 

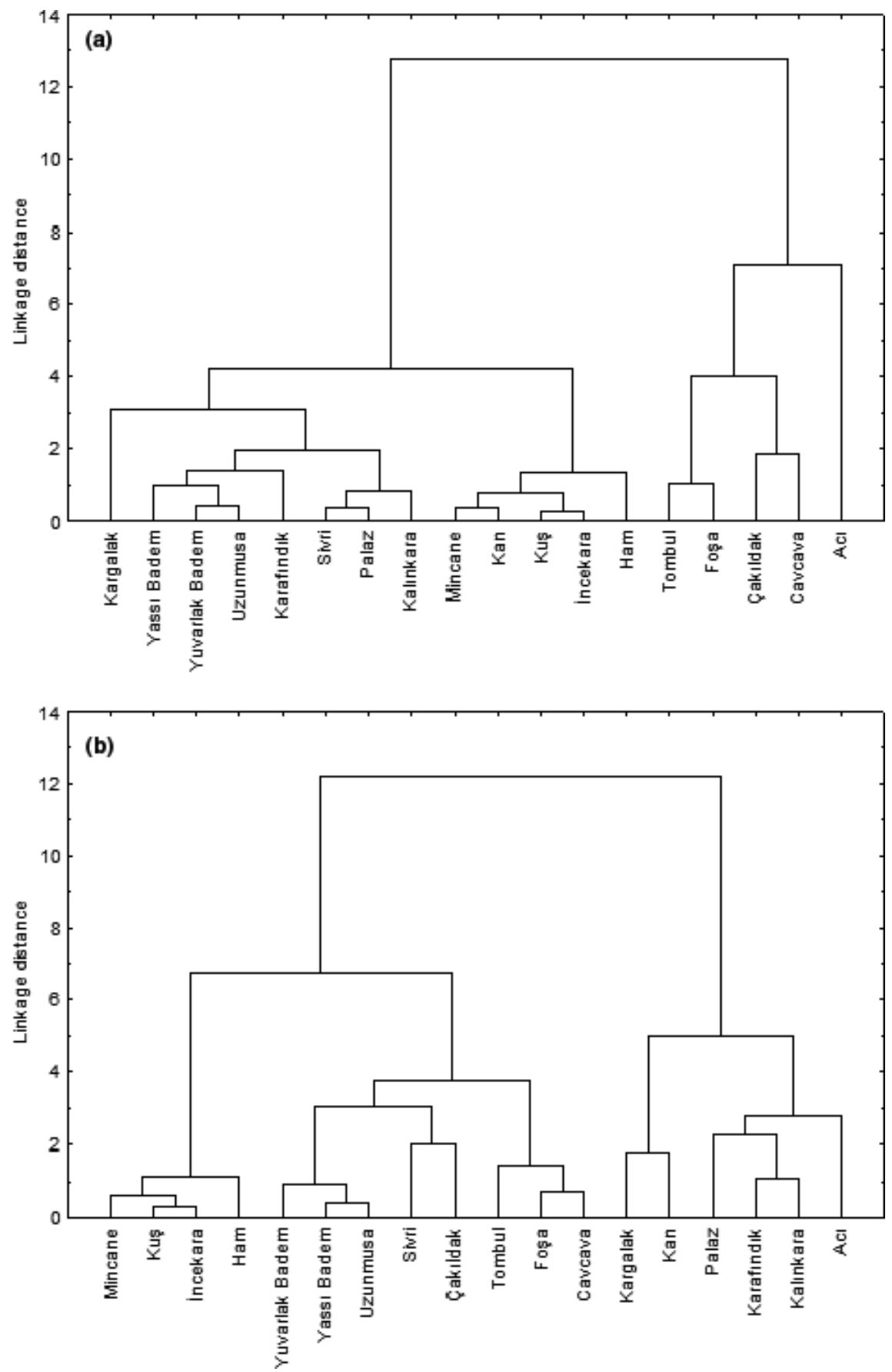

Figure 4 Cluster analyses for e-nose data among eighteen natural (a) and roasted (b) hazelnut varieties.

Badem, Yassı Badem and Uzunmusa), were formed among roasted hazelnuts.

With respect to CA that was also performed to analyse the e-nose data of natural hazelnuts (Fig. 4a), Tombul and Foşa varieties formed a cluster that was close to Çakıldak and Cavcava. However, Acı variety was separated from this cluster. Clusters obtained by CA using e-nose data of natural hazelnuts are in good agreement with the PCA results of the same data set. In Fig. $4 b$, roasted Tombul hazelnut formed a cluster with 
roasted Foșa and Cavcava. The clusters that were formed using the e-nose data are also in good accordance with the PCA results.

\section{Conclusions}

Differences in DSA between natural and roasted hazelnut varieties were observed. DSA showed that roasted hazelnuts can be distinguished from their natural counterparts by certain flavour attributes ('after taste', 'burnt', 'coffee-like', 'roasty/popcorn-like', 'sweet', 'nutty' and 'oily'). Despite the fact that Tombul hazelnut variety may be regarded as one of the best varieties in terms of its sensory attributes and, in general, received the highest intensities, no significant differences $(P>0.05)$ existed among hazelnut varieties except in certain flavour attributes ('after taste' and 'nutty'). With respect to DSA and PCA data, Tombul hazelnut was found to be away from the rest of the varieties in both natural and roasted products. When e-nose data were analysed using PCA, natural Tombul hazelnut had similar aroma profile as that of natural Foşa. For roasted hazelnuts, Foşa and Cavcava varieties had aroma profiles similar to that of Tombul variety. The results obtained by CA are also in good agreement with PCA results of the same data set. It could be concluded that Tombul hazelnut can be discriminated from other varieties using PCA and CA of DSA results, whereas Foşa, Cavcava and Çakıldak had similar aroma profiles as Tombul hazelnut based on e-nose results and their correlation with PCA and CA. Both DSA and e-nose can be used for discrimination of natural and roasted hazelnuts.

\section{Acknowledgments}

This study was funded by TÜBİTAK TOVAG (Under 1001 Programme). We are grateful to the Hazelnut Research Institute for providing the hazelnut varieties.

\section{References}

Alasalvar, C. \& Shahidi, F. (2009). Natural antioxidants in tree nuts. European Journal of Lipid Science and Technology, 111, 10561062.

Alasalvar, C., Shahidi, F. \& Cadwallader, K.R. (2003). Comparison of natural and roasted Turkish Tombul hazelnut (Corylus avellana L.) volatiles and flavor by DHA/GC/MS and descriptive sensory analysis. Journal of Agricultural and Food Chemistry, 51, 50675072.

Alasalvar, C., Odabası, A.Z., Demir, N., Balaban, M.Ö., Shahidi, F. \& Cadwallader, K.R. (2004). Volaties and flavor of five Turkish hazelnut varieties as evaluated by descriptive sensory analysis, electronic nose, and dynamic headspace analysis/gas chromatography-mass spectrometry. Journal of Food Science, 69, SNQ99SNQ106.
Alasalvar, C., Shahidi, F., Amaral, J.S. \& Oliveira, B.P.P. (2009). Compositional characteristics and health effects of hazelnut (Corylus avellana L.): an overview. In: Tree Nuts: Composition, Phytochemicals, and Health Effects (edited by C. Alasalvar \& F. Shahidi). Pp. 185-214. Boca Raton, FL: CRC Press Taylor \& Francis Group.

Alasalvar, C., Pelvan, E. \& Amarowicz, R. (2010a). Effects of roasting on taste-active compounds of Turkish hazelnut varieties (Corylus avellana L.). Journal of Agricultural and Food Chemistry, 58, 86748679.

Alasalvar, C., Pelvan, E. \& Topal, B. (2010b). Effects of roasting on oil and fatty acid composition of Turkish hazelnut varieties (Corylus avellana L.). International Journal of Food Sciences and Nutrition, 61, 630-642.

Burdack-Freitag, A. \& Schieberle, P. (2010). Changes in the key odorants of Italian hazelnuts (Corylus avellana L. Var. Tonda Romana) induced by roasting. Journal of Agricultural and Food Chemistry, 58, 6351-6359.

Cadwallader, K.R. (2010). Isolation and characterization of key flavor constituents of functional foods. Presented at the international Society for nutraceuticals and functional foods annual meeting pre-conference (Nutraceutical ingredients: Challenges, formulations, flavors, regulations, and marketing). Bali, Indonesia, October 11-12.

Drake, M.A., Gerard, P.D., Kleinhenz, J.P. \& Harper, W.J. (2003). Application of an electronic nose to correlate with descriptive sensory analysis of aged Cheddar cheese. Lebensmittel-Wissenschaft und-Technologie, 36, 13-20.

Gardner, J.W. \& Hines, E.L. (1997). Pattern analysis techniques. In: Handbook of Biosensors and Electronic Noses: Medicine, Food and the Environment (edited by E. Kress-Rogers). Pp. 633-652. Boca Raton, FL: CRC Press.

INC (2011). Global Statistics. Reus, Spain: International Nut and Dried Fruit Foundation.

Kadiroğlu, P., Korel, F. \& Tokatli, F. (2011). Classification of Turkish extra virgin olive oils by SAW detector electronic nose. Journal of the American Oil Chemists' Society, 88, 639-645.

Korel, F. \& Balaban, M.Ö. (2002). Microbial and sensory assessment of milk with an electronic nose. Journal of Food Science, 67, 758764.

Langourieux, S., Perren, R. \& Escher, F. (2000). Influence of processing parameters on the aroma of dry-roasted hazelnuts. In: Frontiers of Flavour Science (edited by P. Schieberle \& K.H. Engel). Pp. 527-535. Garching, Germany: Deutsche Forschungsanstalt für Lebensmittelchemie.

Leighton, C.S., Schönfeldt, H.C. \& Kruger, R. (2010). Quantitative descriptive sensory analysis of five different cultivars of sweet potato to determine sensory and textural profiles. Journal of Sensory Studies, 25, 2-18.

Mercanlıgil, S.M., Arslan, P., Alasalvar, C. et al. (2007). Effects of hazelnut-enriched diet on plasma cholesterol and lipoprotein profiles in hypercholesterolemic adult men. European Journal of Clinical Nutrition, 61, 212-220.

Morita, K., Kubota, K. \& Aishima, T. (2003). Comparison of aroma characteristics of 16 fish species by sensory evaluation and gas chromatographic analysis. Journal of the Science of Food and Agriculture, 83, 289-297.

Saklar, S., Katnas, S. \& Ungan, S. (2001). Determination of optimum hazelnut roasting conditions. International Journal of Food Science \& Technology, 36, 271-281.

Yücesan, F.B., Örem, A., Kural, B.V., Örem, C. \& Turan, İ. (2010). Hazelnut consumption decrease the susceptibility of LDL to oxidation, plasma oxidized LDL level and increases the ratio of large/small LDL in normolipidemic healthy subjects. Anatolian Journal of Cardiology, 10, 28-35. 